\title{
Innovative Assessments Help Elucidate Sustained Improvements in Fitness and Metabolic Health in Obese Children
}

\section{Cassandira M Vanderwall ${ }^{1}$, R Randall Clark ${ }^{1}$, Jens C Eickhoff ${ }^{2}$ and Aaron L Carrel ${ }^{2}$}

${ }^{1}$ UW Health- University of Wisconsin Hospitals and Clinics Pediatric Fitness Clinic, USA

${ }^{2}$ Department of Pediatrics, University of Wisconsin School of Medicine and Public Health, USA

Corresponding author: Cassandra M. Vanderwall, University of Wisconsin, 600 Highland Avenue, F4/120, Madison, WI 53792, USA, Tel: 608-263-5210; Fax: 608-262-1636; E-mail: CVanderwall@uwhealth.org

Rec date: August 18, 2016; Acc date: November 14, 2016; Pub date: November 16, 2016

Copyright: (c) 2016 Vanderwall CM, et al. This is an open-access article distributed under the terms of the Creative Commons Attribution License, which permits unrestricted use, distribution, and reproduction in any medium, provided the original author and source are credited.

Citation: Vanderwall CM, Clark RR, Eickhoff JC, Carrel AL, et al. (2016) Innovative assessments help elucidate sustained improvements in fitness and metabolic health in obese children. J Child Obes 1: 22.

\section{ABSTRACT}

Objective: Treatment of childhood obesity is a medical challenge and limited data are available describing successful long term interventions. This study presents a multi-disciplinary intervention that resulted in sustained physiological improvement over a one-year period.

Methods: The criterion outcome variables include cardiovascular fitness (CVF) measured by a populationspecific treadmill test to predict maximal oxygen uptake (predicted $\mathrm{VO}_{2}$ max) and the body composition (BC) variables of fat mass, non-bone lean mass and percent body fat from whole body dual energy x-ray absorptiometry (DXA) scans. Subjects were overweight and obese children $(\mathrm{N}=79)$ evaluated at baseline, 6 and 12 months at a University Hospital-based pediatric fitness clinic.

Results: Statistically significant improvements in non-bone lean body mass $(+4.24 \mathrm{~kg} \pm 5.0, \mathrm{p}<0.0001)$ and predicted $\mathrm{VO}_{2} \max (+0.14 \mathrm{~L} / \mathrm{min} \pm 0.10, \mathrm{p}<0.0001)$ were seen at 6 months. These significant improvements were sustained over 12 months: body fat percentage $(-2.28 \pm 3.49$, $\mathrm{p}<0.0001)$, lean mass $(+6.0 \mathrm{~kg} \pm 4.0, \quad \mathrm{p}<0.0001)$ and predicted $\mathrm{VO}_{2} \max (+0.22 \mathrm{~L} / \mathrm{min} \pm 0.19, \mathrm{p}<0.0001)$. These results were observed despite increases in weight and body mass index (BMI) at 6-months (weight: $+6.6 \mathrm{~kg} \pm 6.93$, $\mathrm{p}<0.0001$; $\mathrm{BMI}:+0.37 \pm 1.21, \mathrm{p}=0.47)$ and 12 -months (weight: $+6.3 \mathrm{~kg} \pm 5.8, \mathrm{p}<0.0001 ; \mathrm{BMI}:+0.91 \pm 2.06$, $\mathrm{p}=0.0002$ ).

Conclusion: These results reflect the sustained effect of a multidisciplinary approach, and the value of using valid and reliable assessment methods to measure sustained physiological changes in a sample of 79 overweight and obese children.

Keywords: Childhood obesity; Cardiovascular fitness; Body composition; Body mass index (BMI); Multidisciplinary clinic; Body fat percentage; Weight management

\section{Introduction}

Childhood obesity is associated with both short- and longterm morbidities including increased cardiovascular risk factors, insulin resistance and type 2 diabetes, hypertension, dyslipidemia, asthma, obstructive sleep apnea, psychosocial problems, decreased quality of life, and increased likelihood of becoming obese adults [1-12]. Poor cardiovascular fitness (CVF) is an independent risk factor for insulin resistance 9 and a strong predictor of morbidity [13-20]. Therefore, assessing CVF and addressing habits that increase risk for obesity early is a key strategy for preventative and therapeutic intervention of childhood obesity [21-25].

Collectively, the aforementioned morbidities associated with childhood obesity highlight the need for individualized assessment and the importance of early intervention to prevent obesity and improve long-term health outcomes. Primary care providers play a pivotal role in the process of preventing, identifying and treating childhood obesity and associated comorbidities [26-31]. However, many providers in the primary care setting feel unable to thoroughly assess the needs and accomplish lifestyle change in these complex patients and families [27-29]. There is a need for specialty clinics that are able to implement evidence-based obesity assessment, prevention and management strategies, such as those described by the American Academy of Pediatrics (AAP), the Alliance for a Healthier Generation, and the Academy of Nutrition and Dietetics (AND) [2,27-35]. At present, long-term outcomes of childhood obesity remain mixed and many providers report frustration with a paucity of long-term data [35]. This may be because providers are unable, or unaware, of useful methods for measuring sustained improvements in fitness in obese children. This cross-sectional study of subjects who completed a one-year clinical intervention aims to augment the literature and provide evidence for alternative methods for measuring and evaluating progress in a pediatric population. 


\section{Materials and methods}

\section{Subjects}

Subjects were 79 children ( $49 \%$ male) with median age of 11 years (4 to 18 years) who were completed a 12-month intervention in the Pediatric Fitness Clinic- a comprehensive weight management program. The sample was predominantly English-speaking (76\%) and half (51\%) utilized private insurance versus public.

\section{Design and setting}

The multidisciplinary weight management intervention included a medical evaluation, individualized consultation from a registered dietitian (RD) and exercise physiologist (EP), and anthropometric, cardiovascular fitness (CVF), dietary and body composition (BC) assessments. The intervention was individualized to the patient and family, and included an initial visit with the entire clinical team, followed by medical reassessment by the physician and follow-up visits with the RD and EP every four weeks for one year. The purpose of the intervention was to assist patients and families achieve better health with improvements in their eating habits, home food environment, cardiovascular fitness via daily physical activity, and self-efficacy towards health behavior change.

\section{Medical evaluation and reassessment}

The physician performed a complete health history and physical examination. This was important to determine the strengths and challenges facing each family prior to beginning lifestyle change and helps direct an individualized care plan. The physical assessment included evaluation of the patient's blood pressure, height, weight, BMI Z-score, and growth. All facets of the medical evaluation are in accordance with evidence-based practices for the assessment of childhood obesity [2,35-43].

\section{Anthropometric and body composition assessment}

Height was measured on a wall-mounted stadiometer to the nearest $0.1(\mathrm{~cm})$. Weight was measured on a calibrated beam balance platform and/or electronic digital platform scale to the nearest $0.1(\mathrm{~kg})$. Body mass index (BMI) was calculated from height and weight measurements. BMI z-score (BMI-z) was determined using the validated formula $\left[Z=\left\{\left[(B M \mid c a l c \div M)^{\wedge} L\right]-1\right\}\right.$ $\div(L \times S)$ ] for age and sex, including the parameters $L, M$ and $S$ for non-Gaussian distributions [4]. Criterion body fat was measured by dual energy x-ray absorptiometry (DXA). Whole body scans were performed with a Norland XR-36 bone densitometer (Norland Corporation, Ft. Atkinson, Wisconsin USA) with subject in supine position by the same investigator. Tissue masses were analyzed using software version 3.7.4/2.1.0. The XR-36 x-ray tube operates at $100 \mathrm{kV}$ and uses dynamic samarium filtration ( $\mathrm{K}$-edge at $46.8 \mathrm{keV}$ ) to produce energy peaks at maximum of 40 and $80 \mathrm{keV}$. The XR-36 uses dynamic filtration to minimize beam hardening. Dual Nal detectors measure the attenuated $x$-ray using a pixel size of $6.5 \times 13.0 \mathrm{~mm}$ and a scan speed of $260 \mathrm{~mm} /$ sec. Whole body DXA scans were performed after subjects removed metal objects or clothing containing metal components. Each scan session was preceded by a calibration routine using multiple quality control phantoms that simulate soft tissue and bone per manufacturer guidelines.

\section{Nutrition assessment, education and counseling}

The team dietitians specialize in pediatric weight management, exercise science and motivational interviewing. Education and counseling are founded on the patient and family's readiness to change, health status and personal priorities. At the initial visit, the RD completed a nutrition behavior screening and utilized a 24-hour dietary recall to collect key information. The RD also assessed the patient's home food environment(s), nutrition role model(s), suspect food insecurities, as well as, dietary patterns of the patient's fellow household members. The RD distributed a 3-day food log to the patient and all family members at the initial visit. Time is reserved at the first follow-up visit to review the food logs and to identify key priorities for behavior change. All subsequent follow-up sessions included careful observation of the nutrition care process for overweight and obese children and adolescents.

\section{Fitness assessment, education and counseling}

The clinical EP assessed the patient and family's fitness level and fitness personalities. At the initial visit, all patients underwent a sub-maximal cardiovascular fitness (CVF) assessment using a treadmill walking protocol to predict maximal oxygen uptake $\left(\mathrm{VO}_{2}\right)$ according to Nemeth (2009); developed and cross-validated on a sample of overweight and obese children [44-45]. The sample CVF is presented in $\mathrm{mL} / \mathrm{kg} / \mathrm{min}$ and $\mathrm{L} / \mathrm{min}$ to recognize that improvements in the predicted $\mathrm{VO}_{2}$ max when measured as $\mathrm{mL} / \mathrm{kg} / \mathrm{min}$ may be due to improvements in the patient's weight [44,46-47]. The EP provided an activity log at the first visit to capture the subject's exercise and movement patterns. The EP provided fitness education and counseling with age-appropriate incentives for accomplished goals at subsequent visits to support improvements in behaviors related to exercise frequency, type, duration, physical activity preferences and screen time.

\section{Motivational interviewing and behavior change}

All investigators engaged in motivational interviewing, shared-decision making and sensitive conversations with subjects and their families. The clinic's philosophy is that a subject's weight is a product of their habits and thus education and counseling are focused on improving habits that are important to the patient and family. Therefore, few conversations focus on a patient's weight and changes in weight [36-41].

\section{Data collection}

Data were collected for subjects who completed the 12month intervention between the years of 2012 to 2015. The University of Wisconsin Human Subjects Committee (Institutional Review Board) approved all procedures. Follow-up visits at 6 and 12 months were defined based on a +/- 3-month window. If there were multiple visits within the $+/-3$ month 
window, then averaged outcome values across the multiple visits were calculated and used for the analyses.

\section{Statistical analysis}

Body composition, CVF, and anthropometric measurements were summarized by standard descriptive statistics using means \pm standard deviations. A linear mixed effects model with subject specific random effects to account for correlations between repeated measures was used to evaluate changes in anthropometric, CVF, and BC measures from the baseline assessment. Changes from baseline to the 6 and 12 month assessments were evaluated using a paired t-test. Normal probability plots and the Shapiro-Wilk test were used to examine the normality assumption. If there was indication that an outcome measure was not normally distributed, then a power transformation was applied before conducting the comparisons. All reported $p$-values were two-sided and $p<0.05$ was used to determine statistical significance. Statistical analyses were performed with SAS software (version 9.3; SAS Institute, Cary, NC).

\section{Results}

The results are presented in Tables 1-2 and Figures 1-2. The baseline demographic, and anthropometric and fitness measurements are presented in Table 1.

Table 1: Baseline demographic and clinical characteristics of study sample captured at baseline.

\begin{tabular}{|c|c|c|}
\hline Parameter & Patients Who Completed One Year N (\%) & P-Value† \\
\hline \multicolumn{3}{|l|}{ Gender } \\
\hline Female & $41(52)$ & 0.832 \\
\hline Male & $38(48)$ & \\
\hline Age (Mean +/- SD) & $11.1 \pm 3.3$ & 0.1136 \\
\hline \multicolumn{2}{|l|}{ Preferred Spoken Language } & 0.001 \\
\hline English & $59(76)$ & \\
\hline Non-English & $19(24)$ & \\
\hline \multicolumn{3}{|c|}{ Anthropometric and Fitness Measures (Mean +/- SD) } \\
\hline Body Mass Index (BMI) & $30.2 \pm 6.4$ & 0.9034 \\
\hline BMI-Z score & $2.1 \pm 0.3$ & 0.0262 \\
\hline Weight (kg) & $71.3 \pm 28.4$ & 0.504 \\
\hline Fitness $\left(\mathrm{VO}_{2} \max , \mathrm{mL} / \mathrm{kg} / \mathrm{min}\right)$ & $33.3 \pm 5.6$ & 0.8765 \\
\hline Fitness $\left(\mathrm{VO}_{2} \max , \mathrm{L} / \mathrm{min}\right)$ & $2.6 \pm 0.7$ & 0.046 \\
\hline Body Fat Percentage (\%) & $38.3 \pm 7.2$ & 0.9477 \\
\hline Lean Body Mass (kg) & $38.2 \pm 13.8$ & 0.5035 \\
\hline
\end{tabular}

Six-month and one year changes in body weight, BMI, BMI Z- weight) and L/min (absolute score), body fat percentage and score, predicted $\mathrm{VO}_{2}$ max in $\mathrm{mL} / \mathrm{kg} / \mathrm{min}$ (standardized for body lean body mass are presented as mean $\pm \mathrm{SD}$ in Table 2 .

Table 2: Mean (SD) absolute changes in anthropometric and fitness measures from baseline to month 6 and month 12 months among all study.

\begin{tabular}{|c|c|c|c|c|c|c|c|c|}
\hline \multirow[t]{2}{*}{ Parameter } & \multicolumn{4}{|c|}{6 Months } & \multicolumn{4}{|c|}{12 Months } \\
\hline & $\mathrm{N}$ & Mean & SD & $\mathrm{p}$-Value $\ddagger$ & $\mathrm{N}$ & Mean & SD & $p$-Value $\ddagger$ \\
\hline Body Mass Index (BMI) & 45 & 0.37 & 1.21 & 0.047 & 79 & 0.91 & 2.06 & 0.0002 \\
\hline BMI-Z score & 45 & -0.05 & 0.13 & 0.0108 & 79 & -0.06 & 0.18 & 0.0025 \\
\hline Weight (kg) & 45 & 6.6 & 6.93 & $<0.0001$ & 79 & 6.3 & 5.8 & $<0.0001$ \\
\hline Fitness $\left(\mathrm{VO}_{2} \max , \mathrm{mL} / \mathrm{kg} / \mathrm{min}\right)$ & 29 & 0.41 & 1.77 & 0.2203 & 71 & 0.26 & 3.37 & 0.5202 \\
\hline
\end{tabular}




\begin{tabular}{|l|c|l|l|l|l|l|l|l|}
\hline Fitness $\left(\mathrm{VO}_{2}\right.$ max, $\left.\mathrm{L} / \mathrm{min}\right)$ & 29 & 0.14 & 0.1 & $<0.0001$ & 71 & 0.22 & 0.19 & $<0.0001$ \\
\hline Body Fat Percentage (\%) & 29 & -0.82 & 2.89 & 0.1387 & 79 & -2.28 & 3.49 & $<0.0001$ \\
\hline Lean Body Mass (kg) & 29 & 4.24 & 5 & $<0.0001$ & 79 & 6.02 & 4 & $<0.0001$ \\
\hline \\
† p-Value for evaluating change from baseline (initial visit, initial assessment)
\end{tabular}

P-values are provided to indicate statistical significance $(p<0.05)$. Statistically significant improvements were seen at 6 months for BMI-z score $(-0.05 \pm 0.13, p=0.0108)$, lean mass $(+4.24 \mathrm{~kg} \pm 5.0, \mathrm{p}<0.0001)$ and predicted $\mathrm{VO}_{2} \max (+0.14 \mathrm{~L} / \mathrm{min} \pm$ $0.10, p<0.0001)$. These improvements were sustained and continued at one year for BMI-z score $(0.06 \pm 0.18, p=0.003)$, lean mass $(+6.0 \mathrm{~kg} \pm 4.0, \mathrm{p}<0.0001)$ and predicted $\mathrm{VO}_{2} \max$ $(+0.22 \mathrm{~L} / \mathrm{min} \pm 0.19, \mathrm{p}<0.0001)$. Additionally, significant improvements in body fat percentage were observed at the oneyear follow-up $(-2.28 \pm 3.49, \mathrm{p}<0.0001)$.
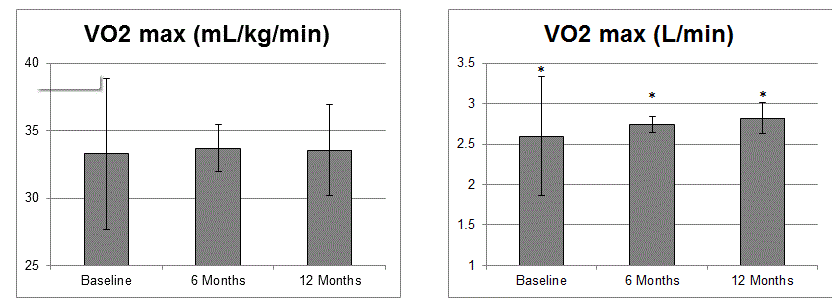

Figure 1: Significant improvements in cardiovascular fitness (CVF) over patient course in a pediatric fitness clinic in patients who completed one year of clinical programming. Mean values displayed with standard deviation (SD) bars. Significance $p<0.05$ indicated by asterisk $(*)$.
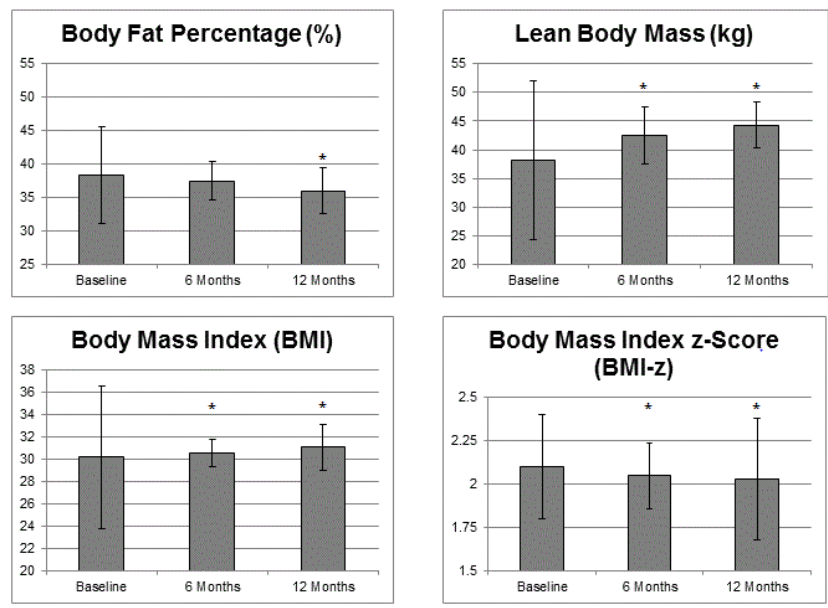

Figure 2: Significant improvements in body composition as compared to body mass index (BMI) over patient course in a pediatric fitness clinic in patients who completed one year of clinical programming. Mean values displayed with standard deviation (SD) bars. Significance $p<0.05$ indicated by asterisk $(*)$.
Figures 1 and 2 illustrate the mean \pm SD values with significance at $\mathrm{p}<0.05$ (indicated by an asterisk). These statistically significant changes in BC and CVF occurred despite significant decreases in BMI-z at 6- and 12-months $(2.05+0.3$, $\mathrm{p}=0.007$ and 2.03+0.35, $\mathrm{p}=0.003$ ), increases in BMI at 6- and 12months $(0.37 \pm 1.121 p=0.047$ and $0.91 \pm 2.06, p<0.001)$ and increasing weight measurements at 6 - and 12-months, respectively $(+6.60 \pm 6.93, p<0.0001$ and $+6.30 \pm 5.80, p<0.0001)$ (Figure 2).

These data support the limitations of monitoring weight and $\mathrm{BMI}$ alone and highlight the utility of other measures to accurately capture and track improvements in BC and CVF.

\section{Discussion}

These data show sustained physiological improvements for 12 months in pediatric patients who successfully completed an evidence-based, multidisciplinary weight management intervention [2,26-34]. Improvements were observed in body composition (increases in lean body mass and decreases in percent body fat), decreases in BMI-z score, and increases in cardiovascular fitness (CVF) over the one year clinical intervention study.

At present, there is an absence of long-term outcomes in the literature for similar measurements of CVF, specifically predicted $\mathrm{VO}_{2}$ max, and body composition using DXA. Most studies present outcomes based on changes in the patient's weight, BMI and BMI z score [35,48-49]. Epstein (2007) describes outcomes from a similar clinical model for study samples with childhood obesity [50]. Improvements in Epstein's analysis for younger children were stronger than those that were observed in the present analysis ( 6 months BMI $z$ score values were: -1.46 versus -0.02 and at 12 months: -1.08 versus -0.05$)$. This discrepancy in improvement may be due to the frequency of follow-up within the Epstein programming. The outcomes for this intervention are more similar to findings from the Strong4Life Obesity Treatment Program who showed changes in BMI z-score values of -0.1 , at $6-12$ months, and -0.2 , at $>12$ months, and thus BMI stabilization [51].

This study also demonstrates the importance of using valid and reliable methods to evaluate improvements in the subject's maximal oxygen uptake (predicted $\mathrm{VO}_{2}$ ) and $\mathrm{BC}$, aside from the commonly presented change in a subject's BMI. Nemet (2005) found that children 6 to 16 years who underwent a weight management intervention had improvements in body fat percentage at 3 -months and 12 -months $(-3.3 \%$ and $-5.9 \%)$ in a small controlled study setting [38]. However, that study used skinfold assessment which has limitations for assessment of BC in an overweight and obese population. Outcomes of the Nemet intervention are attributed to the greater frequency of program 
visits; six nutrition visits in 3 months versus one to two clinic visits in a 3-month period. This supports the benefits of more frequent encounters with a multidisciplinary team and the value of structured exercise programs.

Consistent with the Nemet [38] approach, this study utilized frequent encounters, a multidisciplinary team and structured exercise programs. The goal was to measure the clinical outcomes at baseline, 6-months and 12-months, however some subjects were unable to complete the mid-point evaluation (between the allotted time-frame of three to nine months) and this accounts for our sample size difference at 6-months.

We attribute the sustained changes in our study to three facets of the clinical intervention: (1) evidence-based clinic procedures using valid and reliable methods for assessing change, including assessment of BC and CVF, (2) a multidisciplinary approach that utilized specialized allied healthcare providers at regular intervals, and (3) individualized patient and family-centered care with reliance on motivational interviewing techniques in education, counseling, and goalsetting. The literature supports that healthcare practitioners who utilize facets of motivational interviewing may be well positioned to engage in heath behavior change talk with patients and families [36-41]. A clinician's language, tone, and intention can empower or debilitate a patient and family from making critical health behavior changes [52-55].

This study illustrates that application of evidence-based weight management protocols can produce sustainable health outcomes for overweight and obese youth in a clinical setting [2, 32-34, 40-43]. This study also provides evidence that BMI alone may not represent an individual's progress towards improved health as it does not accurately describe CVF and is not a reliable indicator for significant changes in $\mathrm{BC}$ in overweight and obese children and adolescents [43]. These data demonstrate changes in $\mathrm{BC}$ and CVF that would have been missed with the use of BMI and weight changes alone.

\section{Limitations}

Limitations of the present study include attrition and the assumption that the most complex and most ill patients are often those with the longest care plans. Attrition rates in pediatric obesity clinics have been shown to vary from $49-73 \%$ [56]. The variables explored that correlated with patient attrition are consistent with those in the literature and include nonHispanic black ethnicity, mental health issues, overall health status, difficulty with medical insurance coverage, location and timing of program visits, unfulfilled parental expectations, and a child's desire to leave the program [57-60]. Additionally, we assume that the most complex and/or ill patients require the longest care plans. This skews clinical outcomes since patients who progress more quickly than their counter-parts conclude their clinic course earlier; these patients have more positive short-term changes and thus the clinic does not have long-term follow-up data. This scenario leaves patients who struggle with behavior change but remain dedicated to the program and have more poor outcomes. Additional limitations are that most patients are referred fairly "late" in the process of weight gain/ obesity, as most of the patients had a BMI >99th percentile at baseline. Treatment may be more effective if patients are referred when they are at BMI-for-age percentiles that indicate an increase in risk for overweight (near the 85th percentile) or overweight (85th to 95th percentiles) [2, 28-31, 36-37].

Primary care clinics and patient's families and caregivers play an important role in the screening and treatment of overweight and obesity. These data support that there is a need for greater collaboration among primary care clinics and specialized weight management programs in the prevention of obesity and treatment of overweight and obesity [26-32,61]. Present research supports the need to refer at-risk for overweight and overweight children and adolescents to higher level treatment earlier.

\section{Conclusion}

Interventions are frequently evaluated on basic measures such as changes in the subjects' weight, skinfolds, BMI and BMI z score, and for short duration [35,38,48-49]. However, in the present study the criterion measures to evaluate change included 12 month changes in whole body DXA scans to track subject fat mass, lean body mass and percent body fat and a population-specific treadmill test to evaluate changes in cardiovascular fitness and predicted $\mathrm{VO}_{2}$ max [44-45]. Based on the aforementioned measures, this study indicated that statistically and clinically significant improvements in cardiovascular fitness and body composition could be achieved and sustained over a one year period in a sample of 79 overweight and obese children via an individualized, multidisciplinary clinical intervention.

\section{Acknowledgements}

Research reported was supported by the National Institute of Diabetes and Digestive and Kidney Diseases (NIDDK) of the National Institutes of Health under award number [T32DK077586]. The content is solely the responsibility of the authors and does not necessarily represent the official views of the National Institutes of Health.

The authors want to acknowledge all staff members from the Pediatric Fitness Clinic for their passion, dedication and assistance in collecting data per clinic policies and procedures. This includes Dr. Aaron Carrel, Dr. Alexander Adams, Dr. Blaise Nemeth, Dr. Jennifer Rehm, Randy Clark, Judy Hilgers, Ellen Houston, Stephanie Wolf, Karissa Peyer, Amy Mihm, Amy Caulum, and Cassie Vanderwall.

\section{References}

1. CDC (2010) Obesity task force report.

Barlow SE (2007) AAP Expert Committee. AAP Expert Committee Recommendations Regarding Prevention, Assessment and Treatment of Child Obesity. Pediatrics 120: s164-192.

3. Dietz WH, Robinson TN (2005) Overweight children and adolescents. N Engl J Med 352: 2100-2109.

4. http://www.cdc.gov/obesity/childhood/basics.html 
5. Kuczmarski RJ, Flegal KM (2000) Criteria for definition of overweight in transition: background and recommendations for the United States. Am J Clin Nutr 72:1074-1081.

6. Ogden CL, Li Y, Freedman DS, Borrud LG, Flega KM, et al. (2011) Smoothed percentage body fat percentiles for U.S. children and adolescents, 1999-2004. National health statistics reports 43: 1-7.

7. Ogden CL, Carroll MD, Kit BK, Flegal KM (2014) Prevalence of childhood and adult obesity in the United States, 2011-2012. JAMA 311: 806.

8. Ogden CL, Carroll MD, Kit BK, Flegal KM (2012) Prevalence of obesity and trends in body mass index among US children and adolescents, 1999-2010. JAMA 307:483-490.

9. Endocrine Society. Endocrine Society Guidelines for Childhood Obesity.

10. Holmes ME, Eisenmann JC, Ekkekakis P, Gentile D (2008) Physical activity, stress, and metabolic risk score in 8- to 18 -year-old boys. J Phys Act Health 5: 294-307.

11. Freedman DS, Khan LK, Dietz WH, Srinivasan SR, Berenson GS, et al. (2001) Relationship of childhood obesity to coronary heart disease risk factors in adulthood: the Bogalusa Heart Study. Pediatrics 108: 712-718.

12. Kelly AS, Barlow SE, Rao G, Inge TH, Hayman LL, et al. (2013) American Heart Association Atherosclerosis, Hypertension, and Obesity in the Young Committee of the Council on Cardiovascular Disease in the Young, Council on Nutrition, Physical Activity and Metabolism, and Council on Clinical Cardiology. Severe obesity in children and adolescents: identification, associated health risks, and treatment approaches: a scientific statement from the American Heart Association. Circulation 128: 1689-1712.

13. Blair SN, Cheng Y, Holder JS (2001) Is physical activity or physical fitness more important than defining health benefits? Med Sci Sports Exer 33: S379-S399.

14. Dietz WH (1998) Health consequences of obesity in youth: Childhood predictors of adult disease. Pediatrics 101: 518-525.

15. Lee CD, Blair SN, Jackson AS (1999) Cardiorespiratory fitness, body composition, and all-cause and cardiovascular disease mortality in men. Am J Clin Nutr 69: 373-380.

16. Sinha R, Dufour S, Petersen KF, LeBon V, Enoksson S, et al. (2002) Assessment of skeletal muscle triglyceride content by nuclear magnetic resonance spectroscopy in lean and obese adolescents: relationships to insulin sensitivity, total body fat, and central adiposity. Diabetes 51: 1022-1027.

17. Kelley DE, Goodpaster BH (1999) Effects of physical activity on insulin action and glucose tolerance in obesity. Med Sci Sport Exercise 31: 23.

18. Allen DB, Clark RR, Peterson SE, Eickhoff J, Carrel AL, et al. (2007) Fitness is a stronger predictor of fasting insulin than fatness in overweight male middle-school children. J Pediatr 150: 383-387.

19. Sui X, LaMonte MJ, Laditka JN, Hardin JW, Chase N, et al. (2007) Cardiorespiratory fitness and adiposity as mortality predictors in older adults. JAMA 298: 2507-2516.

20. Wei M, Kampert JB, Barlow CE (1999) Relationship between low cardiorespiratory fitness and mortality in normal-weight, overweight, and obese men. JAMA 282:1547-1553.

21. Brambilla P, Pozzobon G, Pietrobelli A (2011) Physical activity as the main therapeutic tool for metabolic syndrome in childhood. Int J Obesity 35:16-28.
22. Chriqui JF, Economos CD, Henderson K, Kohl HW. III, Kumanyika SK, et al. (2014) Environmental change strategies to promote healthy eating and physical activity and reduce disparities. Childhood obes10: 11-17.

23. Dietz WH (1998) Childhood weight affects adult morbidity and mortality. J Nutr 128: 411S-414S.

24. Kang HS, Gutin B, Barbeau P, Owens S, Lemmon CR, et al. (2002) Physical training improves insulin resistance syndrome markers in obese adolescents. Med Sci Sport Exercise 34:1920-1927.

25. Story $M$ (1999) School-based approaches for preventing and treating obesity. Int J Obes Relat Metab Disord 23: S43-51.

26. Janz KF, Butner KL, Pate RR (2013) The Role of Pediatricians in Increasing Physical Activity in Youth. JAMA Pediatr 1-2.

27. Perrin EM, Finkle JP, Benjamina JT (2007) Obesity prevention and the primary care pediatrician's office. Curr Opin Pediatr 19: 354361.

28. Sothern MS, Gordon ST (2005) Family-based weight management in the pediatric healthcare setting. Obesity Management 1: 197-202.

29. Daniels SR, Hassink SG, Committee on nutrition (2015) The Role of the Pediatrician in Primary Prevention of Obesity. Pediatrics 136; e275.

30. O'Brien SH, Holubkov R, Cohen Reis E (2004) Identification, Evaluation, and Management of Obesity in an Academic Primary Care Center. Pediatrics 114: e154 -e159.

31. Yi-Frazier JP, Larison C, Neff JM, Greves Grow HM, Liu LL, et al. (2012) Obesity in Pediatric Specialty Clinics: An Underestimated Comorbidity. Clin Pediatr 51: 1056-1062.

32. Dietz WH (2015) The Response of the US Centers for Disease Control and Prevention to the Obesity Epidemic. Ann Rev of Pub Health 36: 575-596.

33. Kirk S, Woo JG, Jones WN, Siegel RM (2015) Increased Frequency of Dietitian Visits Is Associated with Improved Body Mass Index Outcomes in Obese Youth Participating in a Comprehensive Pediatric Weight Management Program. Child Obes 11:1.

34. Artandi MK (2012) Conceptual basis and clinical rationale for the development of a multidisciplinary weight management center. Int J Obes 2:S43-S46.

35. Kelishadi R, Azizi-Soleiman F (2014) Controlling childhood obesity: A systematic review on strategies and challenges. J Res Med Sci 19: 993-1008.

36. Fitch A, Fox C, Bauerly K, Gross A, Heim C, Judge-Dietz J, et al. (2013) Institute for Clinical Systems Improvement. Prevention and Management of Obesity for Children and Adolescents.

37. Spear BA, Barlow SE, Ervin C, Ludwig DS, Saelens BE, et al. (2007) Recommendations for Treatment of Child and Adolescent Overweight and Obesity. Pediatrics 120: S254.

38. Nemet D, Barkan S, Epstein Y, Friedland O, Kowen G, et al. (2005) Short- and Long-Term Beneficial Effects of a Combined DietaryBehavioral-Physical Activity Intervention for the Treatment of Childhood Obesity. Pediatrics 115: e443-e449.

39. Ross MM, Kolbash S, Cohen GM, Skelton JA (2010) Multidisciplinary Treatment of Pediatric Obesity: Nutrition Evaluation and Management. Nutr Clin Pract 25: 327-334.

40. Academy of Nutrition and Dietetics Evidence Analysis Library (2007) Evidence-Based Pediatric Weight Management Nutrition Practice Guideline. 
41. Eisenmann JC (2011) Assessment of Obese Children and Adolescents: A Survey of Pediatric Obesity-Management Programs. Pediatrics 128: S51-S58.

42. Krebs NF, Himes JH, Jacobson D, Nicklas TA, Guilday $P$, et al. (2007)Assessment of child and adolescent overweight and obesity. Pediatrics 120: S193-S228.

43. US Preventive Services Task Force (2010) Screening for obesity in children and adolescents: US Preventive Services Task Force Recommendation Statement. Pediatrics 125: 361-367.

44. Nemeth BA, Carrel AL, Clark RR, Peterson S, Sullivan J, et al. (2004) Body habitus is important in predicting vO2max in overweight children utilizing a submaximal test. Med Sci Sports Exerc 36: S1234.

45. Nemeth BA, Carrel AL, Eickhoff JE (2009) Sub-maximal exercise testing predicts maximal VO2 in obese children. Pediatrics 154: 677-681.

46. Ball GDC, Shaibi GQ, Cruz ML, Watkins MP, Weigensberg MJ, et al. (2004) Insulin Sensitivity, Cardiorespiratory Fitness, and Physical Activity in Overweight Hispanic Youth. Obes Res 12: 77-85.

47. Armstrong N, Welsman JR (1994) Assessment and Interpretation of Aerobic Fitness in Children and Adolescents." Exercise and Sport Sciences Reviews 22: 435-476.

48. Whitlock EP, O'Connor EA, Williams SB, Beil TL, Lutz KW, et al. (2008) Effectiveness of Weight Management Programs in Children and Adolescents. Agency for Healthcare Research and Quality.

49. Reynolds KD, Spruijt-Metz D (2006) Translational Research in Childhood Obesity Prevention. Evaluation \& the Health Professions 29: 219-245.

50. Epstein LH, Paluch RA, Roemmich JN, Beecher MD (2007) FamilyBased Obesity Treatment, Then and Now: Twenty-Five Years of Pediatric Obesity Treatment. Health Psychol 26: 381-391.

51. Walsh SM, Palmer W, Welsh JA, Vos MB (2014) Challenges and Successes of a Multidisciplinary Pediatric Obesity Treatment Program. Nutr Clin Pract 29:780-785.
52. Haemer M, Cluett S, Hassink SG, Liu L, Mangarelli C, et al. (2011) Building Capacity for Childhood Obesity Prevention and Treatment in the Medical Community: Call to Action. Pediatrics 128: S71.

53. Brewer K, Pollock N, Wright FV (2014) Addressing the challenges of collaborative goal setting with children and their families. Phys Occup Ther Pediatr 34:138-152.

54. Christie D, Channon S (2014) The potential for motivational interviewing to improve outcomes in the management of diabetes and obesity in paediatric and adult populations: a clinical review. Diabetes Obes Metab 16: 381-387.

55. Walpole B, Dettmer E, Morrongiello BA, McCrindle BW, Hamilton J, et al. (2013) Motivational interviewing to enhance self-efficacy and promote weight loss in overweight and obese adolescents: a randomized controlled trial. J Pediatr Psychol 38: 944-953.

56. Skelton JA, Goff, Jr. DC, Ip E, Beech BM (2011) Attrition in a Multidisciplinary Pediatric Weight Management Clinic. Child Obes 7: 185-193.

57. Eliakim A, Friedland O, Kowen G, Wolach B, Nemet D, et al. (2004) Parental Obesity and Higher Pre-intervention BMI Reduce the Likelihood of a Multidisciplinary Childhood Obesity Program to Succeed - A Clinical Observation. Journal of Pediatric Endocrinology and Metabolism 17: 1055-1062.

58. Gill RS, Karmali S, Hadi G, Al-Adra DP, Shi X, et al. (2012) Predictors of attrition in a multidisciplinary adult weight management clinic. Can J Surg 55: 239-243.

59. Cote MP, Byczkowski T, Kotagal U, Kirk S, Zeller M, et al. (2004) Service quality and attrition: an examination of a pediatric obesity program. Int J Qual Health Care 16:165-173.

60. Barlow SE, Ohlemeyer CL (2006) Parent reasons for non-return to a pediatric weight management program. Clin Pediatr 45: 355360.

61. Hampl S, Paves H, Laubscher K, Eneli I (2011) Patient Engagement and Attrition in Pediatric Obesity Clinics and Programs: Results and Recommendations. Pediatrics 128: s59-s64. 